\title{
Fuzzy Multicriteria Model for Ranking Suppliers in Manufacturing Company
}

\author{
Željko Stević \\ University of East Sarajevo, Faculty of Transport and Traffic Engineering Doboj, \\ Bosnia and Herzegovina \\ llija Tanackov \\ University of Novi Sad, Faculty of Technical Sciences, Serbia \\ Marko Vasiljević \\ University of East Sarajevo, Faculty of Transport and Traffic Engineering Doboj, \\ Bosnia and Herzegovina \\ Slavko Vesković \\ University of Belgrade, Faculty of Transport and Traffic Engineering, Serbia
}

\section{Abstract}

By using the methods of multi-criteria analysis it is possible to make decisions which have significant influence on companies' business. The aim of this paper is to evaluate different suppliers using the integrated model that recognizes a combination of fuzzy AHP (Analytical Hierarchy Process) and the COPRAS method. Based on six criteria, the expert team was formed to compare them, so determination of their significance is being done with fuzzy AHP method. Expert team also compares suppliers according to each criterion and on the base of triangular fuzzy numbers. Based on their inputs, COPRAS method is used to estimate potential solutions. Suggested model accomplishes certain advantages in comparison with previously used traditional models which were used to make decisions about evaluation and choice of supplier. It is vital to make the right decision when selecting a supplier, because the optimal choice ensures lower cost and higher quality of the product itself, and therefore more competitiveness in the market.

Keywords: Multi-criteria decision making, supplier evaluation, Fuzzy AHP, COPRAS, procurement, research, decision support systems

JEL classification: C44, C52, C61, D22, D81, M1 1, L6

\section{Introduction}

Company today must strive to enlarge the quality of product itself, so the end user is satisfied with provides services, what would make him a loyal user. Due to above mentioned it is necessary, during the first phase of logistics, i.e. purchasing logistics, to commit good evaluation and choice of supplier, what can largely influence the forming of product's final price and in that way accomplish significant effect in complete supply chain. It is possible to accomplish the above mentioned if evaluation is being done based on multi-criteria decision making that includes large number of criteria and expert's estimation of their relative significance.

Multi-criteria analysis is rapidly expanding, especially during the past several years, and therefore, big number of problems is being solved nowadays using methods from that area. The AHP method was previously used to address the problem of supplier selection, whether in the conventional form or in a combination with fuzzy logic, for example in Chen et al.(2006), supplier selection for the textile company 
Ertugrul and Karakasoglu (2006), the area of production Chan and Kumar(2007), the area of production TFT-LCD Lee (2009), electronic procurement Benyoucef and Canbolat (2007), in washing machine company Kilincci and Onal (2011), in a gear motor company Ayhan (2013).

For the purpose of suppliers' evaluation, this paper uses the combination of these methods of multi-criteria analysis. Fuzzy AHP (FAHP) had been used for determination of significance of criteria, while COPRAS method was used for suppliers ranking.

This paper is structured as follows. Section 2 shows the fundamentals of conventional analytic hierarchy process, FAHP and Copras method. Section 3 describes main part of this paper: practical example. Section 4 show results of multicriteria model. Section 5 is discussion and section 6 sets out the conclusions and the paper concludes with the references.

\section{Methodology}

Conventional AHP method

Analytic hierarchy process is created by Thomas Saaty (Saaty, 1980) and according to him (Saaty, 2008) AHP is a measurement theory which is dealing with pairs comparing and which relies on expert opinion in order to perform the priority scale. Parts of AHP method are problem decomposition, where the goal is located at the top, followed by criteria and sub-criteria, and at the end of the hierarchy are potential solutions. More details on the AHP are found in the book of Saaty and Vargas (2012).Some key and basic steps in the AHP Methodology are: define the problem, expand the problem taking all the actors into account, the objective and the outcome, identificate criteria with influence on the outcome, structure problem in already explained hierarchy, compare each element with each other at the appropriate level, calculate the maximum value of its own vector, index and degree of consistency.

\section{Chang's extent analysis}

The theory of fuzzy sets was first introduced by Zadeh (1965), whose application enables decision makers to effectively deal with the uncertainties. Fuzzy sets used generally triangular, trapezoidal and Gaussian fuzzy numbers, which convert uncertain fuzzy numbers. Triangular fuzzy numbers (TFN), which were used in this work are marked as $\left(\mathrm{lij}_{\mathrm{ij}} \mathrm{m}_{\mathrm{ij}}, \mathrm{U}_{\mathrm{ij}}\right)$. The parameters $\left(\mathrm{lij}_{\mathrm{ij}}, \mathrm{m}_{\mathrm{ij}}, \mathrm{U}_{\mathrm{ij}}\right)$ are the smallest possible value, the most promising value and highest possible value that describes a fuzzy event, respectively. Let's assume that $X=\left\{x_{1}, x_{2}, \ldots, x_{n}\right\}$ is number of objects, and $U=\left\{U_{1}\right.$, $\left.\mathrm{U}_{2}, \ldots, \mathrm{Um}_{\mathrm{m}}\right\}$ is number of aims.

According to the methodology of extended analysis set up by Chang (1996), for each object an extended goal analysis is made. Valves of the extended analysis "m" for each object can be represented as follows:

$M_{g i}^{1}, M_{g i}^{2}, M_{g i}^{m} i=1,2, \ldots n$.

where $M_{g, j}^{j} j=1,2, \ldots m_{r}$, are TFN.

Chang's expanded analysis includes following steps:

Step 1: Values of fuzzy extension for the i-ti object are given by the equation:

$S_{i}=\sum_{j=1}^{n} M_{g i}^{j} \times\left[\sum_{\mathrm{i}=1}^{\mathrm{n}} \sum_{\mathrm{j}=1}^{\mathrm{m}} M_{g i}^{j}\right]^{-1}$ 
In order to obtain expression

$$
\left[\sum_{i=1}^{\mathrm{n}} \sum_{\mathrm{j}=1}^{\mathrm{m}} M_{g i}^{j}\right]^{-1}
$$

it is necessary to perform additional fuzzy operations with "m" values of the extended analysis, which is represented by the following expressions:

$\sum_{j=1}^{n} M_{g i}^{j}=\left(\sum_{j=1}^{m} l_{j}, \sum_{j=1}^{m} m_{j}, \sum_{j=1}^{m} u_{j}\right)(4)$

$$
\sum_{i=1}^{n} \sum_{j=1}^{n} M_{g i}^{j}=\left(\sum_{i=1}^{n} l_{i}, \sum_{i=1}^{n} m_{i}, \sum_{i=1}^{n} u_{i}\right)
$$

Then it is necessary to calculate the inverse vector:

$$
\left[\sum_{\mathrm{i}=1}^{\mathrm{n}} \sum_{\mathrm{j}=1}^{\mathrm{m}} M_{g i}^{j}\right]^{-1}\left[\frac{1}{\sum_{i=1}^{n} u_{i}}, \frac{1}{\sum_{i=1}^{n} m_{i}}, \frac{1}{\sum_{i=1}^{n} l_{i}}\right]
$$

Step 2: Possibility degree $S_{b}>S_{a}$ is defined:

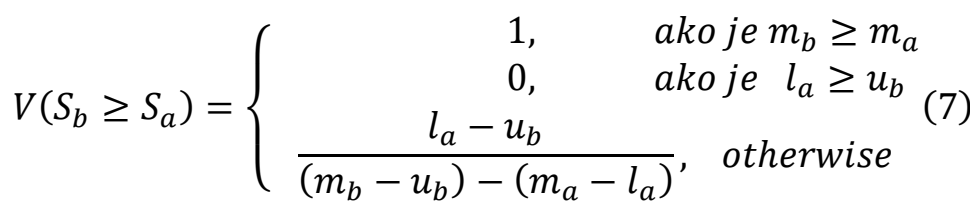

where "d" ordinate of a largest cross-section in point $D$ between $\mu_{\text {sa }}$ and i $\mu_{\text {sb. }}$.

To compare $S_{1}$ and $S_{2}$, both values $V\left(S_{1} \geq S_{2}\right)$ i $V\left(S_{2} \geq S_{1}\right)$ are needed.

Step 3: Level of possibility for convex fuzzy number to be greater than „k" convex number $S_{i}(i=1,2, \ldots, k)$ can be defined as follows:

$$
\begin{gathered}
V\left(S_{i} \geq S_{1}, S_{2}, \ldots, S_{k}\right) \\
=\min V\left(S_{i} \geq S_{k}\right), \quad=w^{\prime}\left(S_{i}\right) \\
d^{\prime}\left(A_{i}\right)=\min V\left(S_{i} \geq S_{k}\right), k \neq i, k=1,2, \ldots, n
\end{gathered}
$$

The weight vector is given by the following expression:

$$
W^{\prime}=\left(\mathrm{d}^{\prime}\left(A_{1}\right), \mathrm{d}^{\prime}\left(A_{2}\right), \ldots, \mathrm{d}^{\prime}\left(A_{n}\right)\right)^{T} \text {, }
$$

Step 4: Through normalization, the weight vector is reduced to the phrase:

$$
W=\left(\mathrm{d}\left(A_{1}\right), \mathrm{d}\left(A_{2}\right), \ldots, \mathrm{d}\left(A_{n}\right)\right)^{T} \text {, }
$$

where $\mathrm{W}$ does not represent fuzzy number.

\section{COPRAS method}

The COPRAS (Complex Proportional ASsessment) method is presented by Zavadskas et al.(1994). Description of COPRAS methods and possibilities of its application are published in a large number of papers Zavadskas et al. (2001), Kaklauskaset al. (2006). The determination of significance and priority of alternatives, by using COPRAS method, can be expressed concisely using next steps:

Step 1: Set the initial decision matrix,

$X=\left[x_{i j}\right]$ 
where $x_{i j}$ is the assessment value of $\mathrm{i}$-th alternative in respect to $\mathrm{j}$-th criterion.

Step 2: Normalize the decision matrix using linear normalization procedure.

About normalization procedures can found in Ginevičius (2007). For normalization in COPRAS method the following formula is used:

$$
\begin{aligned}
& R=\left[r_{i j}\right] \\
& =\frac{x_{i j}}{\sum_{i=1}^{m} x_{i j}}
\end{aligned}
$$

Step 3: Determine the weighted normalized decision matrix $D$, by using the following equation:

$D=\left[x_{i j}\right]=r_{i j} \cdot w_{j}, \quad i=1, \ldots, m, \quad j=1, \ldots, n$

wherer ${ }_{i j}$ is the normalized performance value of $\mathrm{i}$-th alternative on $\mathrm{j}$-th criterion and $\mathrm{w}_{\mathrm{j}}$ is the weight of $j$-th criterion. The sum of weighted normalized values of each criterion is always equal to the weight for that criterion:

$$
\sum_{i=1}^{m} y_{i j}=w_{j}
$$

Step 4: In this step the sums of weighted normalized values are calculated for both the beneficial and non-beneficial criteria by using the following equations:

$$
\begin{gathered}
S_{+i}=\sum_{j=1}^{n} y_{+i j} \\
S_{-i}=\sum_{j=1}^{n} y_{-i j}
\end{gathered}
$$

where $y+i j$ and $y$-ij are the weighted normalized values for the beneficial and nonbeneficial criteria, respectively.

Step 5: The relative weight of i-th alternative is calculated as follows:

$$
Q_{i}=S_{+i}+\frac{\min _{i} S_{-i} \sum_{i=1}^{m} S_{-i}}{S_{-i} \sum_{i=1}^{m} \frac{\min _{i} S_{-i}}{S_{-i}}}(18)
$$

Step 6: Determine the priority order of alternatives. The priority order of compared alternatives is determined on the basis of their relative weight.

$A^{*}=\left\{A_{i} \mid \max _{i} Q_{i}\right\}(19)$

\section{Numerical example}

Criteria applied in this study are: price of materials, pipe length, delivery time, way of payment, mode of delivery and quality hat are still in operation are marked with $\mathrm{C}_{1-}$ $\mathrm{C}_{6}$ respectively. Therefore, there are three criteria, quantitatively expressed and three criteria which are qualitative.Upon criteria establishing, the expert team comprised of three members compared them on the base of triangular fuzzy scale. 
Table 1

Comparison criteria by three experts

\begin{tabular}{cccccccc}
\hline & & $\mathbf{C}_{1}$ & $\mathbf{C}_{2}$ & $\mathrm{C}_{3}$ & $\mathrm{C}_{4}$ & $\mathrm{C}_{5}$ & $\mathrm{C}_{6}$ \\
\hline $\mathbf{C}_{1}$ & $\mathbf{E}_{1}$ & $(1,1,1)$ & $(2 / 3,1,2)$ & $(1 / 2,2 / 3,1)$ & $(1 / 2,1,3 / 2)$ & $(1 / 2,1,3 / 2)$ & $(2 / 3,1,2)$ \\
& $\mathbf{E}_{2}$ & $(1,1,1)$ & $(2 / 3,1,2)$ & $(2 / 3,1,2)$ & $(1,3 / 2,2)$ & $(1 / 2,1,3 / 2)$ & $(2 / 3,1,2)$ \\
& $\mathbf{E}_{3}$ & $(1,1,1)$ & $(1 / 2,2 / 3,1)$ & $(2 / 5,1 / 2,2 / 3)$ & $(1 / 2,1,3 / 2)$ & $(1 / 2,1,3 / 2)$ & $(2 / 7,1 / 3,2 / 5)$ \\
\hline $\mathbf{C}_{2}$ & $\mathbf{E}_{1}$ & $(1 / 2,1,3 / 2)$ & $(1,1,1)$ & $(2 / 3,1,2)$ & $(1,3 / 2,2)$ & $(1,3 / 2,2)$ & $(1,1,1)$ \\
& $\mathbf{E}_{2}$ & $(1 / 2,1,3 / 2)$ & $(1,1,1)$ & $(1,1,1)$ & $(3 / 2,2,5 / 2)$ & $(1,3 / 2,2)$ & $(1,1,1)$ \\
& $\mathbf{E}_{3}$ & $(1,3 / 2,2)$ & $(1,1,1)$ & $(2 / 3,1,2)$ & $(3 / 2,2,5 / 2)$ & $(3 / 2,2,5 / 2)$ & $(2 / 5,1 / 2,2 / 3)$ \\
\hline $\mathbf{C}_{3}$ & $\mathbf{E}_{1}$ & $(1,3 / 2,2)$ & $(1 / 2,1,3 / 2)$ & $(1,1,1)$ & $(3 / 2,2,5 / 2)$ & $(3 / 2,2,5 / 2)$ & $(1 / 2,1,3 / 2)$ \\
& $\mathbf{E}_{2}$ & $(1 / 2,1,3 / 2)$ & $(1,1,1)$ & $(1,1,1)$ & $(3 / 2,2,5 / 2)$ & $(1,3 / 2,2)$ & $(1,1,1)$ \\
& $\mathbf{E}_{3}$ & $(3 / 2,2,5 / 2)$ & $(1 / 2,1,3 / 2)$ & $(1,1,1)$ & $(2,5 / 2,3)$ & $(2,5 / 2,3)$ & $(1 / 2,2 / 3,1)$ \\
\hline $\mathbf{C}_{4}$ & $\mathbf{E}_{1}$ & $(2 / 3,1,2)$ & $(1 / 2,2 / 3,1)$ & $(2 / 5,1 / 2,2 / 3)$ & $(1,1,1)$ & $(1,1,1)$ & $(2 / 3,1,2)$ \\
& $\mathbf{E}_{2}$ & $(1 / 2,2 / 3,1)$ & $(2 / 5,1 / 2,2 / 3)$ & $(2 / 5,1 / 2,2 / 3)$ & $(1,1,1)$ & $(1 / 2,1,3 / 2)$ & $(2 / 5,1 / 2,2 / 3)$ \\
& $\mathbf{E}_{3}$ & $(2 / 3,1,2)$ & $(2 / 5,1 / 2,2 / 3)$ & $(1 / 3,2 / 5,1 / 2)$ & $(1,1,1)$ & $(1,1,1)$ & $(2 / 7,1 / 3,2 / 5)$ \\
\hline $\mathbf{C}_{5}$ & $\mathbf{E}_{1}$ & $(2 / 3,1,2)$ & $(1 / 2,2 / 3,1)$ & $(2 / 5,1 / 2,2 / 3)$ & $(1,1,1)$ & $(1,1,1)$ & $(1 / 2,2 / 3,1)$ \\
& $\mathbf{E}_{2}$ & $(2 / 3,1,2)$ & $(1 / 2,2 / 3,1)$ & $(1 / 2,2 / 3,1)$ & $(2 / 3,1,2)$ & $(1,1,1)$ & $(1 / 2,2 / 3,1)$ \\
& $\mathbf{E}_{3}$ & $(2 / 3,1,2)$ & $(2 / 5,1 / 2,2 / 3)$ & $(1 / 3,2 / 5,1 / 2)$ & $(1,1,1)$ & $(1,1,1)$ & $(2 / 7,1 / 3,2 / 5)$ \\
\hline $\mathbf{C}_{6}$ & $\mathbf{E}_{1}$ & $(1 / 2,1,3 / 2)$ & $(1,1,1)$ & $(2 / 3,1,2)$ & $(1 / 2,1,3 / 2)$ & $(1,3 / 2,2)$ & $(1,1,1)$ \\
& $\mathbf{E}_{2}$ & $(1 / 2,1,3 / 2)$ & $(1,1,1)$ & $(1,1,1)$ & $(3 / 2,2,5 / 2)$ & $(1,3 / 2,2)$ & $(1,1,1)$ \\
& $\mathbf{E}_{3}$ & $(5 / 2,3,7 / 2)$ & $(3 / 2,2,5 / 2)$ & $(1,3 / 2,2)$ & $(5 / 2,3,7 / 2)$ & $(5 / 2,3,7 / 2)$ & $(1,1,1)$ \\
\hline
\end{tabular}

Source: Authors

\section{Results}

After previous describes methodology this section show results of research and their calculation. Fuzzy important weight of the criteria is calculated by taking geometric mean of the responses of the experts Lee (2009), this is shown in Table 2.

Table 2

Fuzzy important weight of the criteria calculated by taking geometric mean

\begin{tabular}{|c|c|c|c|c|c|c|}
\hline & $C_{1}$ & $\mathrm{C}_{2}$ & $\mathrm{C}_{3}$ & $\mathrm{C}_{4}$ & $\mathrm{C}_{5}$ & $\mathrm{C}_{6}$ \\
\hline $\mathrm{C}_{1}$ & $(1,1,1)$ & $\begin{array}{c}(0.606,0.874 \\
1.587)\end{array}$ & $\begin{array}{c}(0.511,0.693 \\
1.817)\end{array}$ & $\begin{array}{c}(0.630,1.145 \\
1.651)\end{array}$ & $(0.5,1,1.5)$ & $\begin{array}{c}(0.503,0.694 \\
1.170)\end{array}$ \\
\hline $\mathrm{C}_{2}$ & $\begin{array}{c}(0.630,1.145 \\
1.651)\end{array}$ & $(1,1,1)$ & $(0.763,1,1.587)$ & $\begin{array}{c}(1.310,1.817 \\
2.31)\end{array}$ & $\begin{array}{c}(1.145,1.651 \\
2.154)\end{array}$ & $\begin{array}{c}(0.737,0.794 \\
0.874)\end{array}$ \\
\hline $\mathrm{C}_{3}$ & $\begin{array}{c}(0.909,1.442 \\
1.957)\end{array}$ & $(0.630,1,1.31)$ & $(1,1,1)$ & $\begin{array}{c}(1.651,2.154 \\
2.657)\end{array}$ & $\begin{array}{c}(1.442,1.957 \\
2.466)\end{array}$ & $\begin{array}{c}(0.630,0.874 \\
1.145)\end{array}$ \\
\hline $\mathrm{C}_{4}$ & $\begin{array}{c}(0.606,0.784 \\
1.587)\end{array}$ & $\begin{array}{c}(0.431,0.550 \\
0.763)\end{array}$ & $\begin{array}{c}(0.376,0.464 \\
0.606)\end{array}$ & $(1,1,1)$ & $\begin{array}{c}(0.794,1 \\
1.145)\end{array}$ & $\begin{array}{c}(0.424,0.550 \\
0.811)\end{array}$ \\
\hline $\mathrm{C}_{5}$ & $(0.667,1,2)$ & $\begin{array}{c}(0.464,0.606 \\
0.874)\end{array}$ & $\begin{array}{c}(0.405,0.511 \\
0.693)\end{array}$ & $(0.874,1,1.26)$ & $(1,1,1)$ & $\begin{array}{c}(0.415,0.529 \\
0.737)\end{array}$ \\
\hline $\mathrm{C}_{6}$ & $\begin{array}{c}(0.855,1.442 \\
1.990)\end{array}$ & $\begin{array}{c}(1.145,1.260 \\
1.357)\end{array}$ & $\begin{array}{c}(0.874,1.145 \\
1.587)\end{array}$ & $\begin{array}{c}(1.233,1.817 \\
2.359)\end{array}$ & $\begin{array}{c}(1.357,1.890 \\
2.41)\end{array}$ & $(1,1,1)$ \\
\hline
\end{tabular}

Source: Authors

Example calculation of geometric mean for $\mathrm{C}_{12}$ is:

$n-=(2 / 3 \times 2 / 3 \times 1 / 2) 1 / 3=0,606$;

$\mathrm{n}=(1 \times 1 \times 2 / 3) 1 / 3=0,874$;

$\mathrm{n}+=(2 \times 2 \times 1) 1 / 3=1,587$

To determine Fuzzy combination expansion for each one of the criteria, first we calculate $\sum_{j=1}^{n} M_{g i}^{j}$ value for each row of the matrix.

$\mathrm{C} 1=(1+0.606+0.511+0.630+0.5+0.503 ; \quad 1+0.874+0.693+1.145+1+0.694 ; \quad 1+1.587+1.817$ $+1.651+1.5+1.17)=(3.75 ; 5.406 ; 8.725)$ etc. 
The $\sum_{i=1}^{n} \sum_{j=1}^{n} M_{g i}^{j}$ value is calculated as:

(3.75; 5.406; 8.725)+(5.585; 7.407; 9.576) +(6.262; 8.427; 10.535)+(3.631; 4.348; $5.912)+(3.825 ; 4.646 ; 6.564)+(6.464 ; 8.554 ; 10.703)=(29.517 ; 38.788 ; 52.015)$

Then, $S_{i}=\sum_{j=1}^{n} M_{g i}^{j} \times\left[\sum_{\mathrm{i}=1}^{\mathrm{n}} \sum_{\mathrm{j}=1}^{\mathrm{m}} M_{g i}^{j}\right]^{-1}$

$S_{1}=(3.75 ; 5.406 ; 8.725) \times(1 / 52.015 ; 1 / 38.788 ; 1 / 29.517)=(0.072 ; 0.139 ; 0.296)$ etc.

Now, the $\mathrm{V}$ values (preference order) are calculated using these vectors.

$$
V\left(\mathrm{~S}_{1} \geq \mathrm{S}_{2}\right)=\frac{0.107-0.296}{(0.139-0.296)-(0.191-0.107)}=0.784
$$

$V\left(\mathrm{~S}_{1} \geq \mathrm{S}_{3}\right)=\frac{0.12-0.296}{-0.157-0.097}=0.693$

$V\left(\mathrm{~S}_{1} \geq \mathrm{S}_{4}\right)=1$;

$V\left(\mathrm{~S}_{1} \geq \mathrm{S}_{6}\right)=\frac{0.124-0.296}{-0.157-0.097}=0.677$

$$
V\left(\mathrm{~S}_{1} \geq \mathrm{S}_{5}\right)=1
$$

The priorities of weights are calculated using:

$d^{\prime}=\left(C_{1}\right) \min (0.784 ; 0.693 ; 1 ; 1 ; 0.677)=0.677$;

$d^{\prime}=\left(C_{2}\right) \min (1 ; 0.887 ; 1 ; 1 ; 0.870)=0.870$

$d^{\prime}=\left(C_{3}\right) \min (1 ; 1 ; 1 ; 1 ; 0.983)=0.983$;

$d^{\prime}=\left(C_{4}\right) \min (0.826 ; 0.541 ; 0.432 ; 0.941 ; 0.411)=0.411$

$\mathrm{d}^{\prime}=\left(\mathrm{C}_{5}\right) \min (0.888 ; 0.618 ; 0.513 ; 1 ; 0.492)=0.492$;

$d^{\prime}=\left(C_{6}\right) \min (1 ; 1 ; 1 ; 1 ; 1 ; 1)=1$

After the equation is applied (10), weight values are obtained, and from the equation (1 1) normalized weights of criteria are received:

$W^{\prime}=(0.677 ; 0.870 ; 0.983 ; 0.411 ; 0.492 ; 1)$;

\section{$\mathbf{W}=(0.15 ; 0.20 ; 0.22 ; 0.09 ; 0.11 ; 0.23)$}

By applying previously described steps of COPRAS method, results represented by the following table were obtained.

Table 3

Ranking of alternatives

Source: Authors

\begin{tabular}{lcccc} 
& $\boldsymbol{S}_{+}$ & $\boldsymbol{S}_{\text {. }}$ & $\mathbf{Q}_{\mathbf{i}}$ & Rank \\
\hline $\boldsymbol{S}_{1}$ & 0.111 & 0.031 & 0.226 & 2 \\
\hline $\boldsymbol{S}_{2}$ & 0.138 & 0.035 & 0.240 & 1 \\
\hline $\boldsymbol{S}_{3}$ & 0.143 & 0.062 & 0.200 & 3 \\
\hline $\boldsymbol{S}_{4}$ & 0.107 & 0.047 & 0.183 & 4 \\
\hline $\boldsymbol{S}_{5}$ & 0.131 & 0.193 & 0.149 & 5 \\
\hline
\end{tabular}

\section{Discussion}

After determination of criteria, it is clear that the third and the sixth criteria are almost equally relevant, i.e. for the company which is subject of research, delivery time and material quality represents the most important criteria during the evaluation of potential suppliers. In table 3 , it is visible that the supplier no. 2 has the highest value and represents the best solution according to previously conducted steps. 


\section{Conclusion}

In its work, expert team which is integral part of the company where the research was done chose suppliers which are competing for the job of securing the purchase system, out of which supplier 2 is most suitable solution. The primary objective and the contribution of this paper the possibility of establishing the long-term cooperation with selected supplier, which will enable the realization of additional benefits.

The evaluation of suppliers may be based on different criteria not only in this, which we used in this paper. Further research will include more criterions for evaluation and combination fuzzy AHP and COPRAS-G methods.

\section{References}

1. Ayhan, M. B. (2013), "A Fuzzy AHP approach for supplier selection problem: a case study in a gear motor company". International Journal of Managing Value and Supply Chains Vol. 4 No.3, pp. 11-23.

2. Benyoucef, M., Canbolat, M. (2007), "Fuzzy AHP-based supplier selection in eprocurement". International Journal of Services and Operations Management, Vol. 3 No.1, pp. 172-192.

3. Chan, F. T., Kumar, N. (2007), "Global supplier development considering risk factors using fuzzy extended AHP-based approach". Omega, Vol. 35 No.4, pp. 417-431.

4. Chang, D. Y. (1996), "Applications of the extent analysis method on fuzzy AHP". European journal of operational research, Vol.95 No.3, pp. 649-655.

5. Chen, C. T., Lin, C. T., Huang, S. F. (2006), "A fuzzy approach for supplier evaluation and selection in supply chain management". International journal of production economics, Vol. 102 No.2, pp. 289-301.

6. Ertugrul, I., Karakasoglu, N. (2006), "The fuzzy analytic hierarchy process for supplier selection and an application in a textile company". Proceedings of 5th international symposium on intelligent manufacturing systems, pp. 195-207.

7. Ginevičius, R. (2008), "Normalization of quantities of various dimensions". Journal of business economics and management, Vol. 9 No.1, pp. 79-86.

8. Kaklauskas, A., Zavadskas, E. K., Raslanas, S., Ginevicius, R., Komka, A., Malinauskas, P. (2006), "Selection of low-e windows in retrofit of public buildings by applying multiple criteria method COPRAS: A Lithuanian case". Energy and Buildings, Vol. 38 No.5, pp. 454-462.

9. Kilincci, O., Onal, S. A. (2011), "Fuzzy AHP approach for supplier selection in a washing machine company". Expert systems with Applications, Vol. 38 No.8, pp. 9656-9664.

10. Lee, A. H. (2009), "A fuzzy supplier selection model with the consideration of benefits, opportunities, costs and risks". Expert systems with applications, Vol. 36 No.2, pp. 28792893.

11. Saaty, T. L. (1980), "The Analytic Hierarchy Process", McGraw-Hill, NewYork

12. Saaty, T. L. (2008), "Decision making with the analytic hierarchy process". International journal of services sciences, Vol. 1 No.1, pp. 83-98.

13. Saaty, T. L., Vargas, L. G. (2012), "Models, methods, concepts \& applications of the analytic hierarchy process"Springer Science \& Business Media Vol. 175.

14. Zadeh, L.A. (1965), "Fuzzy sets". Information and Control, Vol. 8 No.3, pp. 338-353.

15. Zavadskas, E. K., Kaklauskas, A., Kvederyte, N. (2001), "Multivariant design and multiple criteria analysis of a building life cycle". Informatica, Vol.12 No.1, pp. 169-188.

16. Zavadskas, E. K., Kaklauskas, A., Sarka, V. (1994), "The new method of multicriteria complex proportional assessment of projects". Technological and Economic Development of Economy, Vol. 1 No.3, pp. 131-139. 


\section{About the authors}

Željko Stević is a Ph.D. candidate at Faculty of Technical Sciences Novi Sad. Area of interest is logistics. He is author of 25 papers in the field of logistics and transport and one university book. The author can be contacted at zeljkostevic88@yahoo.com.

Ilija Tanackov Ph.D., Full Professor at Faculty of Technical Sciences Novi Sad. Area of interest is transport and logistics. He is the author of many papers, of which about 30 published in $\mathrm{SCl}$ journals. Also, he is the author of a couple of books and participated in a large number of projects. The author can be contacted at ilijat@uns.ac.rs.

Marko Vasiljević Ph.D., Associate Professor at University of East Sarajevo, Faculty of Transport and Traffic Engineering Doboj. Areas of interests are railway traffic and logistics. He is the author of three books and about 70 papers in the areas of interest, of which the few published in $\mathrm{SCl}$ journals. He has participated in over 10 projects, of which the couple and international importance. The author can be contacted at drmarkovasiljevic@gmail.com.

Slavko Vesković Ph.D. is Full Professor at University of Belgrade, Faculty of Transport and Traffic Engineering. Areas of interests are railway traffic and logistics. He is author over 10 papers at $\mathrm{SCl}$ list and a large number of papers at conferences of international importance. He is the head of the large number of projects of international importance. The author can be contacted at veskos@sf.bg.ac.rs. 